\title{
Forecasting Total Ozone Column over Iraq using Artificial Intelligence Approach: a case study for Baghdad Province
}

\author{
Ali M. AL-Salihi, HindK. AL-Jumaily \\ Department of Atmo spheric Science/ College of science / Al-Mustansiriyah University / Baghdad-Iraq
}

\begin{abstract}
The present paper presents a new approach for total ozone column forecasting using an Artificial Neural Network technique for Baghdad, Iraq. Total ozone column data for the period (1979-2000) were used as training and the period (2009-2011) for testing and one year(2012) for forecasting also the combination of meteorological elements have been used as input parameters (stratospheric temperature, Geopotential height and zonal wind). at 50 and $70 \mathrm{mb}$ respectively. The developed ANN models are being applied for aimed at providing forecasts in a near real time schedule, different network types were tested with different kinds of input information. Preliminary tests showed that a generalized feed forward ANN model using Gaussian activation function achieved the optimum forecasting of total ozone column. To calculate differences between measured and forecasted values of total ozone column, root mean square error (RMSE), mean absolute error (MAE), Relative error $(R E)$ and determination coefficient $\left(R^{2}\right)$ were calculated. According to four statistical indices were determined in order to examine the accuracy of the optimum ANN model, it was found that the more accurate model among the four considered statistical indices were RMSE, MAE, RE and $R^{2}$ was 0.05244, 0.0392, 0.4709 and 0.9974 respectively, these results show that ANN forecasts of total ozone column over Baghdad have superiority and highly satisfactory especially for a high variable gas like ozone.
\end{abstract}

Keywords:Artificial Intelligence, Neural Network, Total ozone, Baghdad, Iraq

\section{INTRODUCTION}

The ozone gas is a layer in Earth's atmosphere which contains relatively high concentrations of ozone $\left(\mathrm{O}_{3}\right)$. This layer absorbs about $90 \%$ of the sun's high frequency such as ultraviolet radiation, which is potentially damaging to life on earth. Over $90 \%$ of the ozone in Earth's atmosphere is present in stratosphere [1]. It is mainly located in the lower portion of the stratosphere from approximately $10 \mathrm{~km}$ to $50 \mathrm{~km}$ above Earth, though the thickness varies seasonally and geographically [2]. The ozone layer is not really a layer at all, but has become known as such because most ozone particles are scattered between 19 and 30 kilometers (12 to 30 miles) up in the Earth's atmosphere, in a region called the stratosphere. The concentration of ozone in the ozone layer is usually under 10 parts ozone per million [3]. Ozone is a secondary pollutant and is not usually emitted directly from stacks, but instead is formed in the atmosphere as a result of reactions between other pollutants emitted mostly by industries and automobiles that is produced from photochemical reactions between volatile organic compounds $\left(\operatorname{voc}_{\mathrm{s}}\right)$ and nitrogen oxides $\left(\mathrm{NO}_{\mathrm{x}}\right)$ under the existence of sunlight [4]. The ( $\left.\operatorname{voc}_{\mathrm{s}}\right)$ and $\left(\mathrm{NO}_{\mathrm{x}}\right)$ together are called precursors of ozone the ozone precursors can be from both human- made (anthropogenic) and natural (biogenic) sources. Motor vehicle exhaust, industrial emission, gas station and chemical solvents are some of the major anthropogenic sources of $\mathrm{NO}_{\mathrm{x}}$ and $\mathrm{voc}_{\mathrm{s}}$. Many species of biogenic sources including trees and plants emit hydrocarbon and fertilized soils release NOx. In suitable ambient meteorological condition (e.g. warm, sunny/clear day) ultraviolet radiation (UV) causes the precursors to interact photo-chemically in a set of reactions that result in the formation of ozone. The process of ozone formation can be expressed as [5-14].

$$
\begin{gathered}
\mathrm{NO}_{2}+\mathrm{UV} \rightarrow \mathrm{NO}+\mathrm{O} \\
\mathrm{O}+\mathrm{O}_{2}+\mathrm{M} \rightarrow \mathrm{O}_{3}+\mathrm{M}
\end{gathered}
$$

Where, $\mathrm{M}$ is a third body molecule that remains unchanged in the reaction. Ozone produced this way gets simultaneously destroyed as:

$$
\mathrm{O}_{3}+\mathrm{D} \rightarrow \mathrm{DO}+\mathrm{O}_{2}
$$

Where, D implies additional reactant that destroys the ozone via oxidation Because of its capability to absorb the incoming radiation, the stratospheric ozone is a major source of stratospheric heating, which further heats the troposphere. Again, because of radiation of IR the tropopause gets some cooling. Thus, stratospheric ozone exerts both heating and cooling effect on the land-troposphere system. Total ozone is a measure of the numberof ozone molecules between the ground and the top of the atmosphere. In a more mathematical language, total ozone is simply the integral of the ozone concentration with respect to height. A literature survey by the authors of the present contribution has shown that statistical time series analysis approach in forecasting the atmospheric and environment pollution has been proved viable by a number of researchers,But, in recent times, artificial neural network (ANN) has been proposed by many scientists as a better alternative to the 
conventional regression approach in forecasting time series pertaining to complex atmospheric and environmental phenomena. Since formation of ozone is a highly intricate phenomenon, a number of researchers have concentrated on its prediction and consequently comparative studies have been carried out to discern the performance of ANN over conventional regression approach in predicting ozone over different cities[15-17].In a number of case studies where they established supremacy of ANN over customary methodologies in ozone forecasting .An artificial neural network (ANN)providesa computationally efficient way of determining an empirical, possibly nonlinear relationship betweena number of inputs and one or more outputs. ANN has been applied for modeling, identification, optimization, prediction, forecasting and control of complex systems. ANN models are type of prediction models and there have been several articles that have used artificial neural networks for predicting total ozone column .The present paper employee Artificial Neural Network (ANN) Approach to forecasting total ozone column in Baghdad city based mean air temperature, Geopotential Height and zonal wind.

\section{ARTIFICIALNEURALNETWORK}

Artificial neural networks (ANNs) were introduced by Mcculloch and Pitts in 1943 [18]. They represent parallel working systems, which consist of a number of processing units interconnected in a network, these units are called neurons. ANNs consist of a number of elements called neurons. These neurons are grouped together to form a layer. Each neuron has a number of inputs and a single output. Each input has an assigned factor or parameter called the weight. Neural networks generally consist of a number of interconnected processing elements. The interneuron connections are arranged and the nature of the connection determine the structure of network. Neural networks can be classified according to their strictures into followingtype [19].

1-Feed forward network: In a feed forward network the neurons are generally grouped in to layers. Signals flow always from the input layer through to the output layer via unidirectional connections, the neurons being connected from one layer to the next, but not it in same layer.

2- Recurrent network: In recurrent network, the outputs of some neurons are feed back to the same neurons or to neurons in preceding layers. Therefore, signals can flow in both forward and backward directions.

There are two main features make neural networks a very useful tool in solving prediction and modeling problems. Those features are; their ability to learn and generalize. Learning process depend on providing a set of training data, which used to adjust the network weights, using a described learning algorithm. After training process have been successfully achieved, the network will be able to recognize a certain output when a newly data is presented to its input layer. This is what we mean by generalization. Finding the network weights, such that the difference between the network output and the desired output; is the main job of the ANN learning algorithm. ANNs have been used both to estimate parameters of a formal model and to learn to emulate the process model itself to predict future outcomes. ANNs have been successfully used to solve a variety of prediction and forecasting problems. The network consist of three layers: an input layer, hidden layer and output layer. The input layer consist of all the input factors: information from the input layer is then processed in the course of one hidden layer; the output vector is computed in the final (output) layer. Generally the hidden and output layers have activation functions. The dashed lines in figure 1 mean that there are more neurons in each layer than represented in this figure. The time series prediction problem using a neural network approach can be separated into threesuccessive steps or sub problem [20-23].

I. Neural network architecture.

II. The learning or training process.

III .The testing

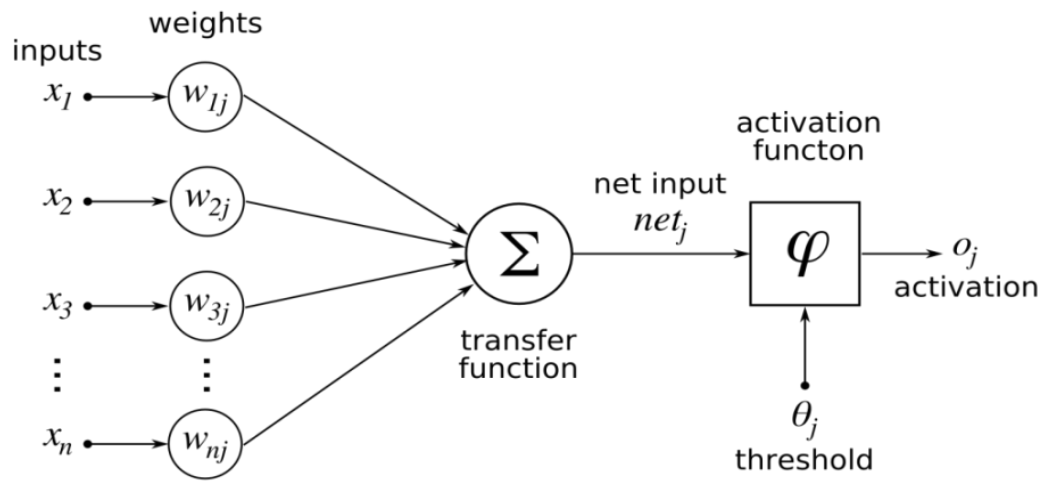

Figure(1): Schematic diagram of neural network[20]. 
In the present study a multi-layer feed forward network based on back propagation learning procedure is designed for estimating the total ozone column.

\section{Methodology}

In the present paper, Artificial Intelligence (AI) approach which represented by single and multilayer ANN has been developed for forecasting the total ozone column. Artificial Neural Networks are loosely based on biological neural systems, in that they are made up of an interconnected system of nodes (neurons) as shown in figure 1. An ANN can identify patterns in numeric data in a somewhat analogous fashion to the learning process in its biological counterpart (i.e. by accumulated experience or training) [24]. Neurons usually operate in parallel and are configured in regular architectures. They are often organized in layers, and feedback connections both within the layer and toward adjacent layers are allowed. Each feedback connection is expressed by a numerical value called as weight, which can be modified. They are basically stored in three types of layers i.e. input layer, hidden layer and output layer. The output of a node is scaled by connecting weights and fed forward to as input to the nodes in the next layer of the network implying a direction of information processing. The multilayer ANN has the ability to learn through the training. Training requires a set of training data which consists of a series of input which represented by upper air data such as air temperature, geopotential height and zonal wind at two atmospheric level (50 and $70 \mathrm{mb})$. During the training, multilayer ANN is repeatedly presented with the training data and the weights are adjusted in the network from time to time till the desired error goal is reached in the output (total ozone column). In the present study, the respective data of the 6 meteorological parameters for the duration of 408 months was split into three parts viz. 360 months of the data was used in training the ANN model and 36 months was used in testing and validation while the remaining was used in validating the model while the remain 12 months was used in forecasting. Contrary to the 'rule of thumb' to find the optimal number of neurons in the hidden layers used by the other researchers, the present study used the iterative approach for higher accuracy in forecasting [25-26]. The architecture of the ANN model was varied by changing both the number of neurons in the hidden layer as shown in figure 3 , and the number of epochs which are the steps in training the model. Starting from 2 neurons, the model formulation went up to 12 neurons with an incremental factor of 1 neurons in each respective model. Based on the learning rate, each set of neurons was trained at 10000 and 30000 iteration, with variation hidden layers from 1 to 3 hidden layers subsequently, 450 ANN models were formulated and tested in the present study. In order to get the optimal Artificial Neural Network architecture, various Algorithms with different number of neurons and hidden layers and transfer functions including (Sigmoid, Hyperbolic Tangent, Hyperbolic Secant) were investigated, 450 experiment of training Algorithms were tested in order to determine the most appropriate for the training process.

Many alternate training-processes have different variants are available such as back-propagation. The goal of any training algorithm is to minimize the global error, such as root mean squared error (RMS E), mean absolute error (MAE).Relative error (RE)and Determination coefficient $\left(\mathrm{R}^{2}\right)$.

$$
R M S E=\sqrt{\frac{1}{n} \sum_{i=1}^{n}(o-t)^{2}}
$$

In addition, Determination Coefficient $\left(\mathrm{R}^{2}\right)$. Relative error (RE) and mean absolute error (MAE) are defined as follows, respectively

$$
\begin{gathered}
M A E=\frac{1}{n} \sum_{i=1}^{n}\left|\frac{o-t}{t}\right| \\
R^{2}=1-\left[\frac{\sum(t-o)^{2}}{\sum(t-\bar{t})^{2}}\right] \\
R E=\frac{|t-o|}{t} * 100 \%
\end{gathered}
$$

Where $\mathrm{t}$ is measured, $\mathrm{o}$ is output and $\mathrm{n}$ is number of observations [27].

$\mathrm{ANN}_{\mathrm{S}}$ have been used in a broad range of applications including pattern classification, function approximation, optimization, prediction, and automatic control[28].The back-propagation algorithm has been used in feedforward single hidden layers. 


$$
f(x)=\operatorname{sech}(x)(5)
$$

Where $\mathrm{X}$ is the weighted sum of inputs.

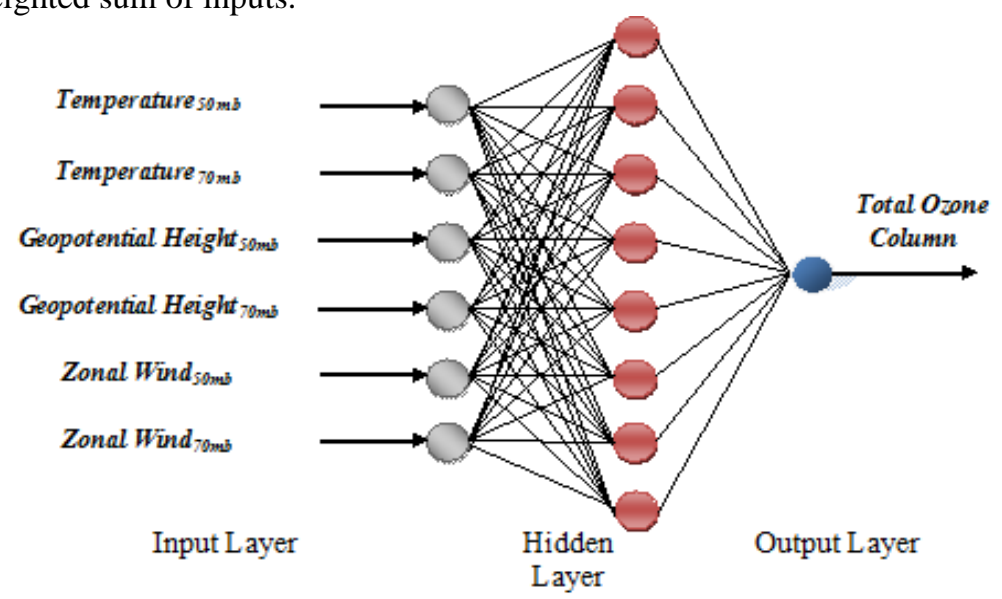

Figure (2):The architecture of neural network.

\section{SITE DESCRIPTION AND CLIMATE}

Baghdad is the capital and the commercial center of Iraq, it is located on a vast plain bisected by the river Tigris as shown in Figure 3, also it has Facilities of electrical power plants, oil refineries like Al-Dora refinery and tanneries and textile mills. The population of Baghdad in 2012 was approximately 7, 216, 040. Iraq's official statistical reports give the total land area as $438,446 \mathrm{~km}^{2}$, It is the largest city in Arab world (after Cairo/Egypt) and the second largest city in Western Asia (after Tehran/Iran). Baghdad is located on flat terrain with no hills or other obstruction around; it is surrounded by flat uncultivated desert, it has a subtropical arid climate according to Köppen climate classification and is, in terms of maximum temperatures, one of the hottest cities in the world. In the summer from June to August, the average maximum temperature is as high as $44{ }^{\circ} \mathrm{C}$ accompanied by blazing sunshine. Humidity is very low (usually under $10 \%$ ) due to Baghdad's distance from the marshy Arabian Gulf, dust storms from the deserts to the west are a normal occurrence during the summer [29] Winters boast mild days and variable nights. From December to February, Baghdad has maximum temperatures averaging 15.5 to $18.5^{\circ} \mathrm{C}$, though highs above $21{ }^{\circ} \mathrm{C}$. Morning temperatures can be chilly: the average January low is $3.8^{\circ} \mathrm{C}$. Annual rainfall, almost entirely confined to the period from November to March, averages around $150 \mathrm{~mm}$, but has been as high as $338 \mathrm{~mm}$ and as low as $37 \mathrm{~mm}$ [30].
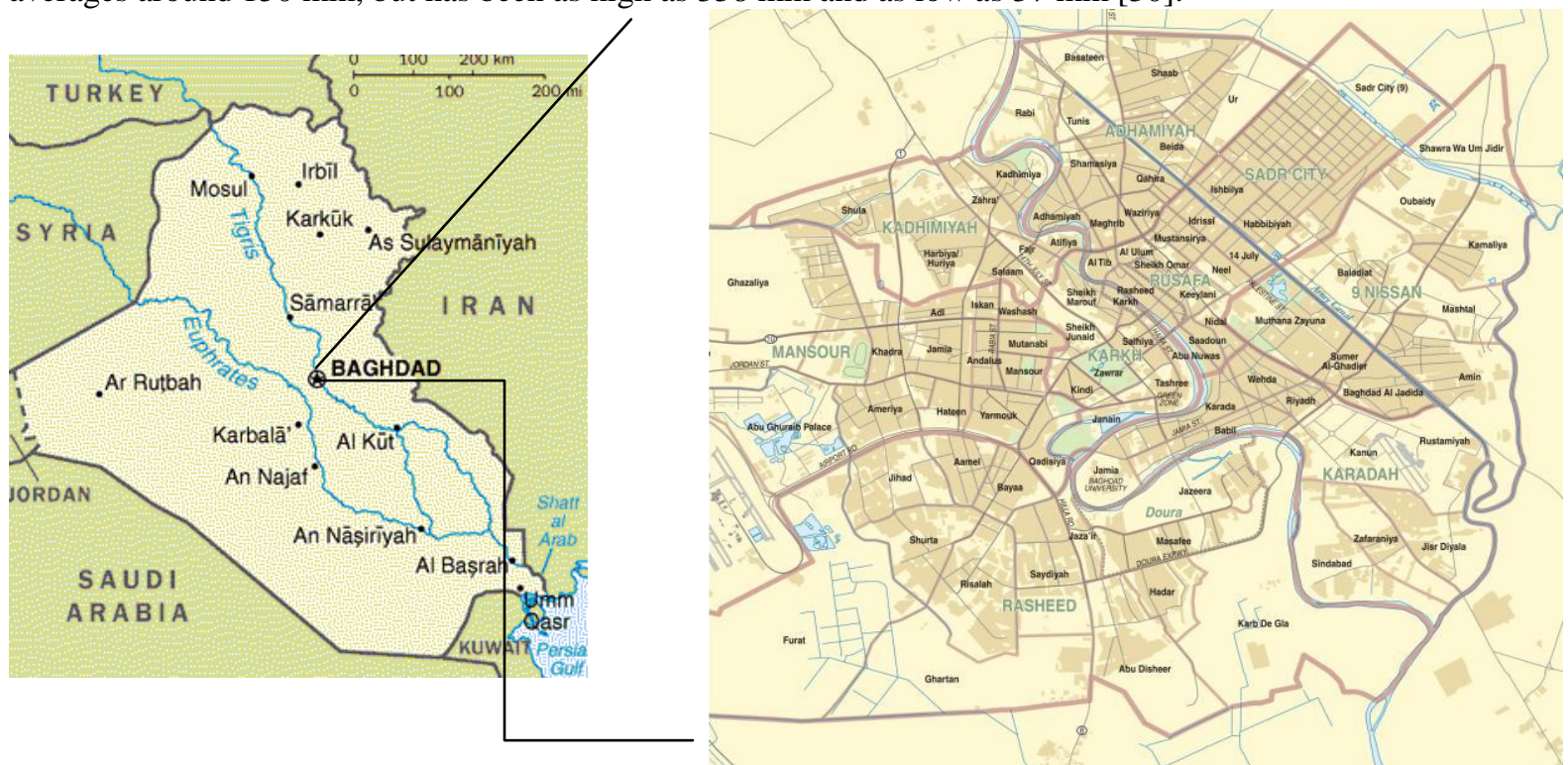

Figure (3): Map of Iraq with location of the study Area [29]. 


\section{Results And Discussion}

The performance of the ANN models during training, testing and forecasting procedure were evaluated on the basis of the following statistical error tests: Root Mean Square Error (RMSE), Mean Absolute Error (MAE), Relative error (RE) and coefficient of determination $\left(\mathrm{R}^{2}\right)$ as shown in Tables 1,2 and 3 respectively. ANN model 5 is superior to other ANN the models because it has the smallest errors. The MAE are 0.0339, $0.00261,0.0392$, the RMSE $0.080516,0.0086,0.0524$,. Relative error 12.1929, 0.0939, 0.4709, coefficient of determination (R2 value) of ANN model 5are found to be $0.746913,0.998666,0.9974$ which implies that ANN model 5 provides an accurate estimation of monthly mean daily total ozone Column of Baghdad as shown in figures 3,4 and 5 the performance of training, testing and forecasting with actual against the total ozone column data calculated by ANN approach were plotted for the optimum ANN model which represented by ANN model 5. The results indicate that most of the points fall along the diagonal line and the degree of the deviation from the diagonal line is small. So comparison results indicate that ANN model provides the best results among the ten models. That is, ANN model 5 is superior to the other ANN models, most of the points fall along the diagonal line. That is, ANN model 5 is superior to the other ANN models, most of the points fall along the diagonal line. The forecasted values have good agreement with the measured values. It can also be seen from the comparison of ANN model $(1-10)$ that the dispersion degree of ANN model 5 is smaller than the other ANN models which indicate that the ANN model 5 provided the best estimations among all the proposed models. Tables 1-3 show that ANN has the minimum predictions errors in Baghdad city. Low values of forecasting errors for Baghdad province confirm the ability of the ANN models to predict total ozone column values precisely.These results demonstrate the generalization capability of the ANN model and its ability to produce accurateestimates in Baghdad and other Iraqi province.

Table1. Prediction errors for monthly mean daily TOC often ANN for training stage.

\begin{tabular}{|c|c|c|c|c|c|c|}
\hline $\begin{array}{c}\text { Model } \\
\text { no }\end{array}$ & $\begin{array}{c}\text { Architectureof } \\
\text { ANN }\end{array}$ & $\begin{array}{c}\text { Activation } \\
\text { Function }\end{array}$ & RMSE & $\mathrm{R}^{2}$ & $\% \mathrm{RE}$ & MAE \\
\hline 1 & 6.10 .1 & Gaussian & 0.080563 & 0.746590 & 12.1761 & 0.0338 \\
\hline 2 & 6.6 .4 .1 & $\mathrm{e}^{-\mathrm{x}}$ & 0.080575 & 0.746498 & 12.3195 & 0.0342 \\
\hline 3 & 6.9 .1 & Gaussian & 0.080028 & 0.750582 & 11.7998 & 0.0328 \\
\hline 4 & 6.6 .4 .1 & Sec & 0.080396 & 0.747857 & 12.1201 & 0.0337 \\
\hline 5 & 6.8 .1 & Gaussian & 0.080516 & 0.746913 & 12.1929 & 0.0339 \\
\hline 6 & 6.6 .5 .1 & Gaussian & 0.080870 & 0.744814 & 12.2807 & 0.0341 \\
\hline 7 & 6.12 .10 .1 & Gaussian & 0.077728 & 0.766930 & 11.8697 & 0.0310 \\
\hline 8 & 6.6 .7 .1 & Gaussian & 0.080662 & 0.745856 & 12.0659 & 0.0335 \\
\hline 9 & 6.12 .8 .1 & Gaussian & 0.079133 & 0.756939 & 11.9325 & 0.0331 \\
\hline 10 & 6.6 .2 .1 & Gaussian & 0.080640 & 0.746095 & 12.1790 & 0.0338 \\
\hline
\end{tabular}

Table2. Prediction errors for monthly mean daily TOC of ten ANN for testing stage.

\begin{tabular}{|c|c|c|c|c|c|c|}
\hline $\begin{array}{c}\text { Model } \\
\text { no }\end{array}$ & $\begin{array}{c}\text { Architectureof } \\
\text { ANN }\end{array}$ & $\begin{array}{c}\text { Activation } \\
\text { Function }\end{array}$ & RMSE & $\mathrm{R}^{2}$ & $\% \mathrm{RE}$ & MAE \\
\hline 1 & 6.10 .1 & Gaussian & 0.019038 & 0.993465 & 0.1947 & 0.00540 \\
\hline 2 & 6.6 .4 .1 & $\mathrm{e}^{-\mathrm{x}}$ & 0.031773 & 0.981643 & 0.2932 & 0.00813 \\
\hline 3 & 6.9 .1 & Gaussian & 0.006396 & 0.999266 & 0.0484 & 0.00134 \\
\hline 4 & 6.6 .4 .1 & Sec & 0.048243 & 0.957109 & 0.4423 & 0.01230 \\
\hline 5 & 6.8 .1 & Gaussian & 0.008675 & 0.998666 & 0.0939 & 0.00261 \\
\hline 6 & 6.6 .5 .1 & Gaussian & 0.022071 & 0.991318 & 0.2375 & 0.00660 \\
\hline 7 & 6.12 .10 .1 & Gaussian & 0.022109 & 0.991296 & 0.2247 & 0.00623 \\
\hline 8 & 6.6 .7 .1 & Gaussian & 0.015886 & 0.995535 & 0.1617 & 0.00450 \\
\hline 9 & 6.12 .8 .1 & Gaussian & 0.019694 & 0.993097 & 0.1969 & 0.00547 \\
\hline 10 & 6.6 .2 .1 & Gaussian & 0.061192 & 0.930109 & 0.5867 & 0.01630 \\
\hline
\end{tabular}


Forecasting Total Ozone Column over Iraq using Artificial Intelligence Approach: A case study

Table3. Prediction errors for monthly mean daily TOC of ten ANN for forecasting stage.

\begin{tabular}{|c|c|c|c|c|c|c|}
\hline $\begin{array}{c}\text { Model } \\
\text { no }\end{array}$ & $\begin{array}{c}\text { Architectureof } \\
\text { ANN }\end{array}$ & $\begin{array}{c}\text { Activation } \\
\text { Function }\end{array}$ & RMSE & $\mathrm{R}^{2}$ & $\%$ RE & MAE \\
\hline 1 & 6.10 .1 & Gaussian & 0.05642 & 0.9970 & 0.5189 & 0.0432 \\
\hline 2 & 6.6 .4 .1 & $\mathrm{e}^{-\mathrm{x}}$ & 0.06868 & 0.9954 & 0.6437 & 0.0536 \\
\hline 3 & 6.9 .1 & Gaussian & 0.06231 & 0.9964 & 0.5684 & 0.0474 \\
\hline 4 & 6.6 .4 .1 & Sec & 0.05640 & 0.9970 & 0.5189 & 0.0432 \\
\hline 5 & 6.8 .1 & Gaussian & 0.05244 & 0.9974 & 0.4709 & 0.0392 \\
\hline 6 & 6.6 .5 .1 & Gaussian & 0.10008 & 0.9903 & 1.0331 & 0.0861 \\
\hline 7 & 6.12 .10 .1 & Gaussian & 0.05679 & 0.9969 & 0.5857 & 0.0488 \\
\hline 8 & 6.6 .7 .1 & Gaussian & 0.10839 & 0.9880 & 1.1265 & 0.0939 \\
\hline 9 & 6.12 .8 .1 & Gaussian & 0.07095 & 0.9954 & 0.6502 & 0.0542 \\
\hline 10 & 6.6 .2 .1 & Gaussian & 0.06013 & 0.9965 & 0.5894 & 0.0491 \\
\hline
\end{tabular}

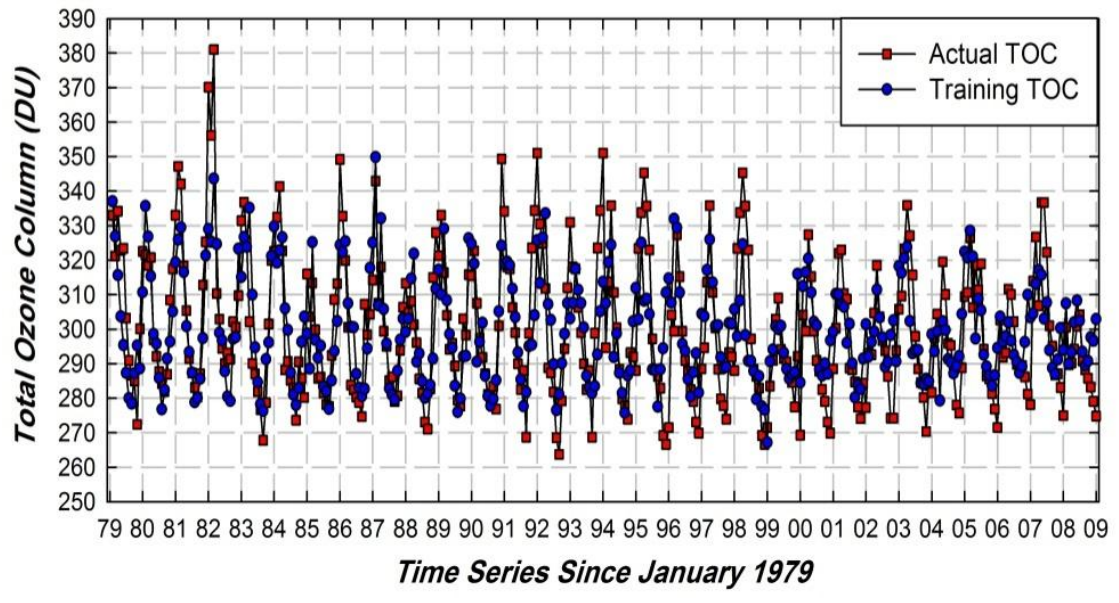

Datafortrainingprocedure.

Figure(4):Comparison betweentheactualandestimatedtotalozonecolumn

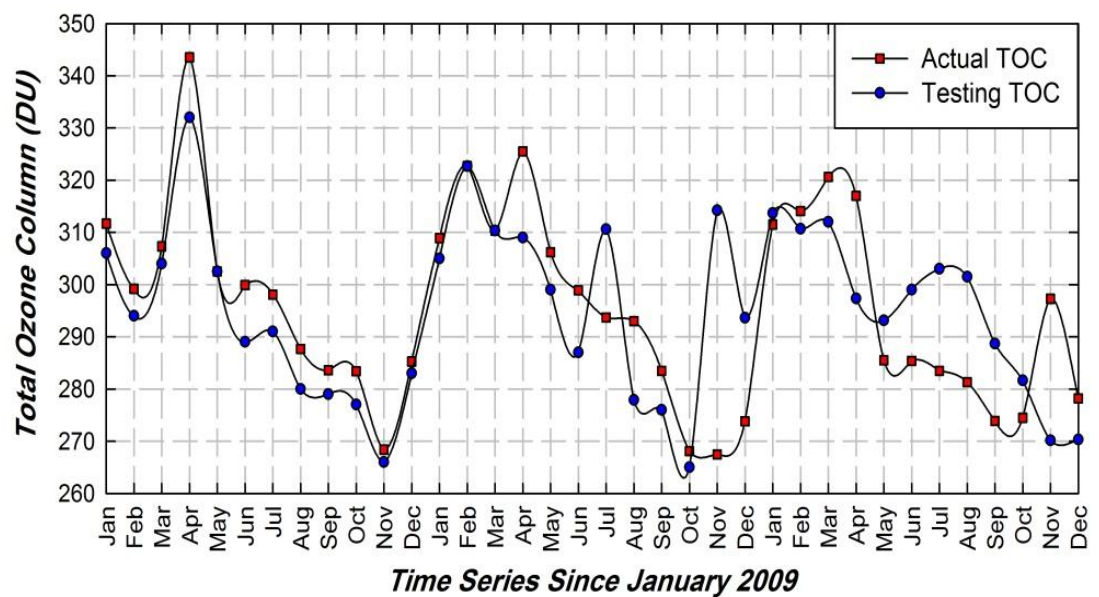

Figure(5):Comparisonbetweentheactualandestimatedtotalozonecolumn Datafortestingprocedure. 


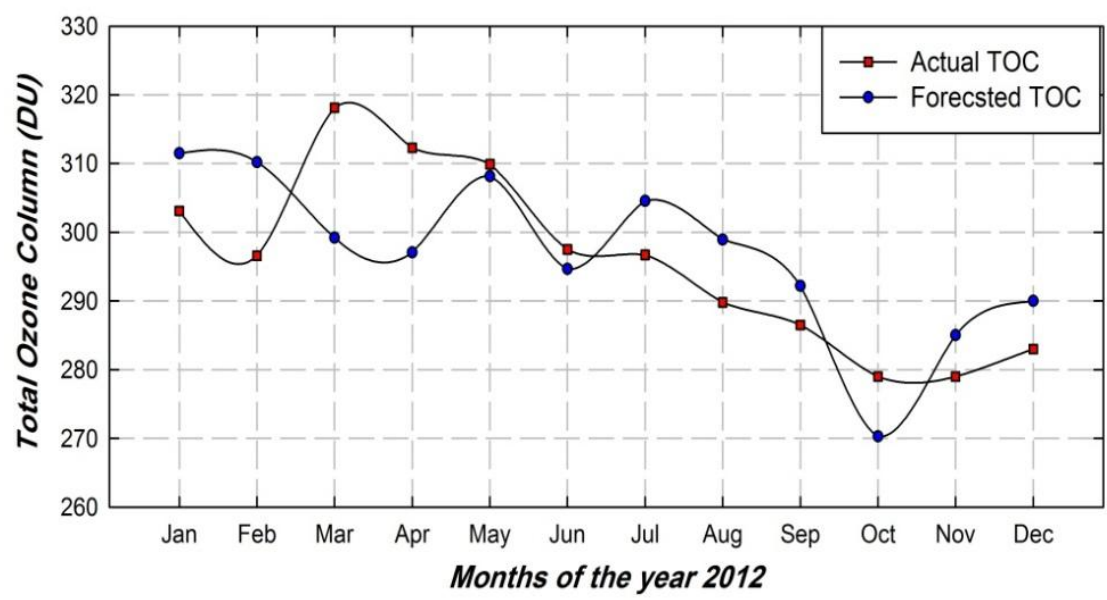

Figure(6):Comparison betweentheactualandestimatedtotalozonecolumn

Dataforforecastingprocedure.

\section{Conclusion}

In this paper, ANN techniques are used to estimate monthly average total ozone column in Baghdad city, Iraq. The developed ANN models have six input parameter with different number of hidden layers, neurons number, learning rates varied from 10000 to 30000 iteration based on four transformation function (Sigmoid, Hyperbolic Tangent, Hyperbolic Secant). The ANN architecture that provides the optimum performance has eight neurons in the hidden layer and Gaussian as activation function with single hidden layer. The model 5 made estimation with MAE of 0.0392, RMSE of 0.05244, RE of 0.4709 and $\mathrm{R}^{2}$ of 0.997 through the forecasting stage were superior to the forecasts of the other proposed ANN models. This study confirms the ability of the ANN to estimate total ozone column values precisely. Therefore, the proposed ANN model 5 will be suitable for forecasting total ozone column at other locations in Iraq employing limited upper air data.

\section{Reference}

[1]. VA ZQUEZ, M., \& HANSLMEIER, A. (2006).Ultraviolet radiation in the solar system.Dordrecht, Netherlands, Springer.

[2]. JOSEFSSON, W. (2000).Measurements of total ozone 1997 -1999.Norrkoping, Swedish Meteorologica 1 and Hydrologica 1 Institute.

[3]. CHRISTIE, M. (2000).Ozone layer a philosophy of science perspective . Cambridge, Cambridge University Press.

[4]. MURRELL, J. C., \& KELLY, D. P. (1996). Microbiology of atmospheric trace gases: sources, sink s and global change processes. Berlin, Springer.

[5]. NEWMAN, M. C., \& CLEMENTS, W. H. (2008).Ecotoxicology: a comprehensive treatment. Boca Raton, CRC Press.

[6]. DE MORA, S. J., DEMERS, S., \& VERNET, M. (2000). The effects of UV radiation in the marine environment.Cambridge, Cambridge University Press.

[7]. HELBLING, E. W., \& ZAGARESE, H. (2003).UV effects in aquatic organisms and ecosystems. Cambridge, Royal Society of Chemistr y.

[8]. THERAMONGKOL, P. (2001).Intelligent ozone-level forecasting using artificial neural network.Ottawa, Nationa 1 Library of Canada.

[9]. EANN (CONFERENCE), JAYNE, C., YUE, S., \& ILIADIS, L. S. (2012).Engineering applications of neural networks 13th International Conference, EANN 2012, London, UK, September 20-23, 2012, proceedings. Heidelberg, Springer.

[10]. THERAMONGKOL, P. (2001).Intelligent ozone-level forecasting using artificial neural network. Ottawa, Nationa 1 Library of Canada.

[11]. MONGE-SANZ, B., \& MEDRANO-MARQUES, N. (2003).Artificia 1 Neural Networks Applications for Total Ozone Time Series.Lecture Notes in Computer Science. 806-814.

[12]. MONGE SANZ, B. M., \& MEDRANO MARQUES, N. J. (n.d.).Total ozone time series analysis: a neural network model approach Nonlinear Processes in Geophysics.

[13]. ZHANG, W. (2010).Computational ecology artificial neural networks and their applications. Singapore, WorldScientific.

[14]. MU LlER, M. D., KAIFEL, A. K., WEBER, M., TELlMANN, S., BURROWS, J. P., \&LOYOLA, D. (2003). Ozone profile retrieval from Global Ozone Monitor ing Experiment (GOME) data using a neural network approach (Neural Network Ozone Retrieval System (NNORSY)). Journal of Geophysical Research: Atmospheres. 108.

[15]. CHATTOPADHYAY, G., \& CHATTOPADHYAY, S. (2009). Predicting da ilytota l ozone over Kolkata, India: skill assessment of different neural network models. Meteorological Applications.16, 179- 190.15 CHATTOPADHYAY, G., \& CHATTOPADHYAY, S. (2009). Predicting da ilytota 1 ozone over Kolkata, India: skill assessment of different neural network models. Meteorological Applications.16, 179- 190.

[16]. CHATTOPADHYAY S.,\& CHATTOPADHYAY G. (2012). Modeling and Prediction of Monthly Tota 1 Ozone Concentrations by Use of an Artificial Neural Network Based on Principal Component Analys is. Pure and Applied Geophysics.169, 1891-1908.

[17]. CHATTOPADHYAY, S., \& BANDYOPADHYAY, G. (2007). Artificia 1 neuralnetwork with backpropagation learning to predict mean monthly total ozone in Arosa, Switzer land.International Journal of Remote Sensing.28, 4471-4482.

[18]. ANDERSON, J. A. (1995).An introduction to neural networks. Cambridge, Mass, MIT Press 
[19]. LESHIK, E. A., \& CRALLE, J. (2011).An introduction to algorithmic trading basic to advanced strategies. Chichester, U.K., Wiley.

[20]. REED, R. D., \& MARKS, R. J. (1999).Neural smithing supervised learning in feedforward artificial neural networks. Cambridge , Mass, MIT Press.

[21]. SAPUAN, S. M., \& MUJTABA, I. M. (2010).Composite materials technology: neural network applications. Boca Raton, CRC Press.

[22]. TAKEFUJI, Y. (1992).Neural Network Parallel Computing . Boston, MA, Springer US. http://dx.doi.org/10.1007/978-1- 46153642 .

[23]. KRASNOPOL' SKY, V. M. (2013). The application of neural networks in the earth system sciences neural networks emulations for comp lex multidimensional mappings. Dordrecht.

[24]. HAUPT, S. E., PASINI, A., \& MARZBAN, C. (2009).Artificial intelligence methods in the environmental sciences.[New York, NY], Springer.

[25]. PEARSON, D. W., STEELE, N. C., \& ALBRECHT, R. F. (2003). Artificial Neural Nets and Genetic Algorithms Proceedings of the International Conference in Roanne, France, 2003. Vienna, Springer Vienna.

[26]. GRAUPE, D. (2013).Principles of Artificial Neural Networks.Singapore, World Scientific Publishing Company.

[27]. WILKS, D. S. (2006).Statistical methods in the atmospheric sciences. Amsterdam, Academic Press.

[28]. LIU, J. (2013).Radial basis function (RBF) neural network control for mechanical systems design, analysis and Matlabsimulation.Berlin, Springer.

[29]. NATIONAL GEOGRAPHIC SOCIETY (U.S.). (2008). National Geographic atlas of the Middle East. Washington, DC, Nationa 1 Geographic.

[30]. Iraqi Meteorological Organization and Se ismology (IMOS). Unpublished climate reports,.2012, Baghdad. 